\title{
The application of a new, innovative, hybrid technology combining hardfacing and nitriding to increase the durability of forging tools
}

\author{
Marcin Kaszuba ${ }^{1}$ (D)
}

Received: 11 August 2020 / Revised: 16 September 2020 / Accepted: 18 September 2020

(c) The Author(s) 2020

\begin{abstract}
The article deals with the wear of forging tools used in hot forging processes. The research presented in the work includes analysis of tool life used in a selected industrial hot die forging process. Multiple treatment variants were used to increase wear resistance, including thermo-chemical treatment (nitriding), welding methods (surfacing) and an innovative new hybrid technology combining surfacing and nitriding. First of all, the research focused on determining the impact of the phase structure of the nitrided layers used and the surfacing layer on resistance to destructive factors occurring in the analyzed process. Next, hybrid treated tools combining surfacing and nitriding were also subjected to operational tests. Each of the tools analyzed in this work was operated until it was withdrawn due to excessive wear, and then subjected to comprehensive analysis. The tests of tools after operation included: surface scanning to determine the amount of wear of the analyzed tools after work, microhardness measurement, and microscopic tests. A detailed analysis of changes in the surface layer of tools in selected areas was made using a scanning microscope. The aim of the study was to assess the effectiveness of the hybrid surface treatment process used to increase the wear resistance of the surface layer of tools and thereby improve the durability of the forged tools analyzed. The obtained research results indicate a beneficial effect of using the new technology resulting in $300 \%$ increase in the durability of the analyzed tools. The effect of improving durability confirmed by obtained results arises from the use of hybrid layers, which are more resistant to abrasive wear and to cracking due to thermo-mechanical fatigue. Moreover, the study shows that nitriding may have a beneficial influence on improving the lifetime of forging tools, under the condition that the nitrided layer has an $\alpha$ diffusive layer structure, without a larger amount of $\gamma^{\prime}$ and $\varepsilon$ nitride precipitates.
\end{abstract}

Keywords Forging tool $\cdot$ Durability $\cdot$ Hot forging $\cdot$ Surfacing $\cdot$ Nitriding $\cdot$ Wear

\section{Introduction}

The lifetime of tools applied in industrial manufacturing processes is one of the primary factors deciding the efficiency of a given production process [1]. Metal forming processes, including hot die forging processes, where tools are very complicated and expensive to make and tool costs may even reach up to $30 \%$ of total production costs, are a special group of manufacturing processes characterized by low tool lifetime [2].

The low lifetime of forging tools arises from heavy working conditions. The factors having a decisive influence on

Marcin Kaszuba

marcin.kaszuba@pwr.edu.pl

1 Department of Metal Forming, Welding and Metrology, Wroclaw University of Science and Technology,

Lukasiewicza Street 5, Wrocław, Poland tool life are: high temperature, which may reach a value even up to $800{ }^{\circ} \mathrm{C}$ in the surface layer at the instant of material deformation, after which intensive cooling takes place, periodically variable loads of a value locally exceeding even $3000 \mathrm{MPa}$, and intensive friction. As a result of the action of the aforementioned factors during operation, destructive phenomena occur in the area of the surface layer [3].

Much information can be found in the available literature on the subject of destructive phenomena; however, classifications of these mechanisms vary [3]. Research conducted until now indicates that the following wear mechanisms occur in the surface layer of dies: abrasive wear, thermo-mechanical fatigue, plastic deformation, fatigue cracking, adhesive wear, and oxidation [4]. The intensity of individual destructive mechanisms is also affected by the shape of the tool's working impression, which locally determines the change of conditions such as duration of contact, friction path and others. In areas 
where there is a long friction path under high load, the dominant mechanism is abrasive wear [5, 6]. Oxidation and tempering of the surface layer occurs at sites exposed to long-lasting contact with the hot material of the forging, and in combination with high loads, this may lead to plastic deformations. Moreover, a mesh of cracks typical of thermo-mechanical fatigue is frequently observed throughout the entire surface [7]. The impact of the aforementioned mechanisms on tool lifetime is generally analyzed separately for each mechanism, and no precise, global physical description of the wear process is known that would account for all phenomena simultaneously, just as they occur in reality [8].

Issues concerning tool lifetime have recently been gaining significance, particularly from the perspective of improving the efficiency of forging processes and improving the quality of manufactured forgings. In relation to the above, the pursuit of improving the lifetime of forging equipment is ever-present in forging technology. In industrial practice, many methods are applied to improve the lifetime of forging tools. Measures to improve tool lifetime are generally taken in three different directions. First of all, technological and designing aspects of the forging process are taken into consideration. The second direction pertains to modification of the material from which tools are made. The third direction is modern surface engineering techniques [9]. The most widespread techniques include welding techniques (hardfacing), thermochemical processing (nitriding, nitrocarburizing), beam techniques, mechanical methods (shot peening), as well as hybrid layers and techniques [10]. Among the methods listed above, nitriding is the most well-mastered and commonly applied method of improving the lifetime of forging tools in the world [11]. The nitriding process can be carried out in several ways, including by means of gaseous atmospheres, fluid beds, powder mixtures and salt baths. Regardless of the method applied, conducted studies have demonstrated that for nitriding to effectively improve the lifetime of forging tools, the obtained nitrided layer must have a specific, uniform structure. Among the structural types of nitrided layers that can be obtained, a layer made up of $\gamma^{\prime}$ nitrides and carbonitrides contributes to increased resistance to abrasion and scoring as well as to increased corrosion resistance. Nitrided layers with a surface zone of the $\varepsilon$ phase are generally characterized by inferior functional properties, mainly because they exhibit low ductility simultaneously with high resistance to abrasion, which makes them suitable for processes where there are lower dynamic loads. However, in forging tool applications, the best properties are exhibited by nitrided layers without compound zones, which are characterized by very good fatigue strength and are less susceptible to cracking due to thermal fatigue, which makes them suitable for work under conditions of high dynamic loads [12].
Recently, hardfacing, including regenerative surfacing, is becoming a more and more popular technique of improving lifetime. This is due to the development of welding techniques, particularly from the perspective of new materials with increasingly better properties, which now meet the requirements posed towards forging tools. The most popular hardfacing methods for forging tools currently include: shielded metal arc welding, welding with self-shielded powder wire, submerged arc welding (with electrode wire or electrode tape), MIG welding (with solid or powder wire), MAG welding (with solid or powder wire), the powderplasma method and TIG welding. The application of a given method is generally decided by the shape of the tool to be hardfaced, the expected thickness of the hardfaced layer, and the required quality of the pad weld [13]. Regardless of the above, proper selection of the hardfacing material, which ensures improvement of resistance to abrasive and adhesive wear, thermo-mechanical fatigue, plastic deformation and corrosion, has a decisive influence on the lifetime of hardfaced tools. Due to this, most recent studies have been oriented towards the selection of materials dedicated for making the pad weld, similar to the base material of the tool [14].

Based on the positive effects of applying the aforementioned solutions to improve the lifetime of forging tools, which have been tried and tested in many industrial forging processes [15-18], it was decided to combine both hardfacing and nitriding methods into one, hybrid surface treatment process. It should be emphasized that this solution has been filed for patent protection under the name "Method of improving the lifetime of a forging tool through modification of its surface layer"[19]. This article presents the results of laboratory tests conducted on samples and forging tools subjected to industrial operating tests.

\section{Methodology}

The front wheel hot die forging process was selected for tests of forging tool lifetime. The selected process is performed on a Massey crank press with a pressing force of $25 \mathrm{MN}$ in three operations: the first is upset forging, the second is preliminary die forging, and the third is finish forging (Fig. 1). The initial temperature of the stock material is $1150-1180{ }^{\circ} \mathrm{C}$ (forging occurs at a similar temperature). The material of the forging is $20 \mathrm{HG}$ steel $(20 \mathrm{MnCr} 5$ according to ISO standard). The tools are made from 1.2343 hot-work tool steel (H11/X37CrMoV5-1 according to ISO standard).

The lifetime of individual tools differs in the analyzed process. The lowest lifetime is displayed by the bottom die used in the 2nd forging operation, amounting to approx. $7000 \mathrm{k}$ forgings on average. In relation to the above, this die was specifically chosen for tests (Fig. 1). It should be 


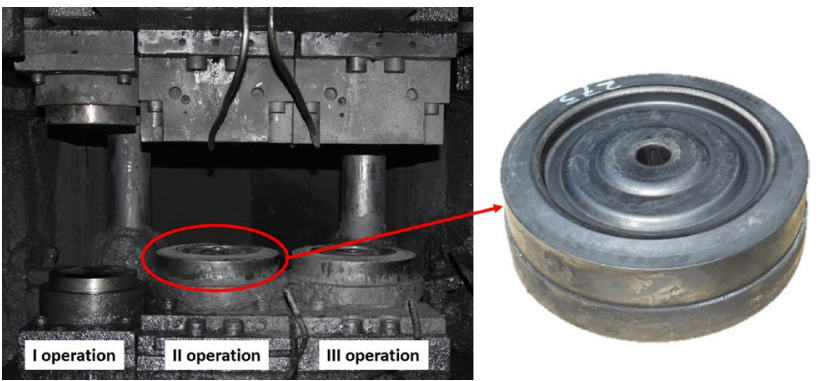

Fig. 1 Massey 2500T press with set of forging tools with selected analyzed analyzed die from the second operation

emphasized that it is standard in this process to apply nitriding as the method for improving lifetime, which is why it was decided to first select the type of nitrided layer ensuring the longest lifetime of the die in the analyzed process.

Conducted tests covered tools on which five variants of treatment were applied for the purpose of improving lifetime, and these variants are presented in Table 1.

\subsection{Preparation of tools for tests}

All of the analyzed tools were initially subjected to the same heat treatment, typical for this grade of steel, based on hardening and double tempering.

Dies no. 1, no. 2, no. 3 (and no. 5) were subjected to the controlled ZeroFlow nitriding process [22]. This method allows for performance of the nitriding process under controlled conditions, making it possible to obtain layers of a similar thickness but varied phase structure $\left(\varepsilon+\gamma^{\prime}+\alpha\right.$, $\gamma^{\prime}+\alpha$ or $\alpha$ layers). It was assumed that the goal would be to obtain a diffusive layer with an effective thickness of $0.13-0.15 \mathrm{~mm}$, which is the typical thickness of layers applied for forging tools. The next significant parameter of the nitriding process is nitriding potential, which was selected based on the Lehrer-Małdziński diagram (Fig. 2).

Such a potential was adopted in order for nitrided dies to obtain a specific phase structure: diffusive (precipitative) zone layer $\alpha$ (die no. 1), layer consisting of a zone of $\gamma^{\prime}$ iron nitride and precipitative zone $\alpha$ (die no. 2) or layer consisting of a zone of $\varepsilon+\gamma^{\prime}$ iron nitrides and precipitative zone $\alpha$

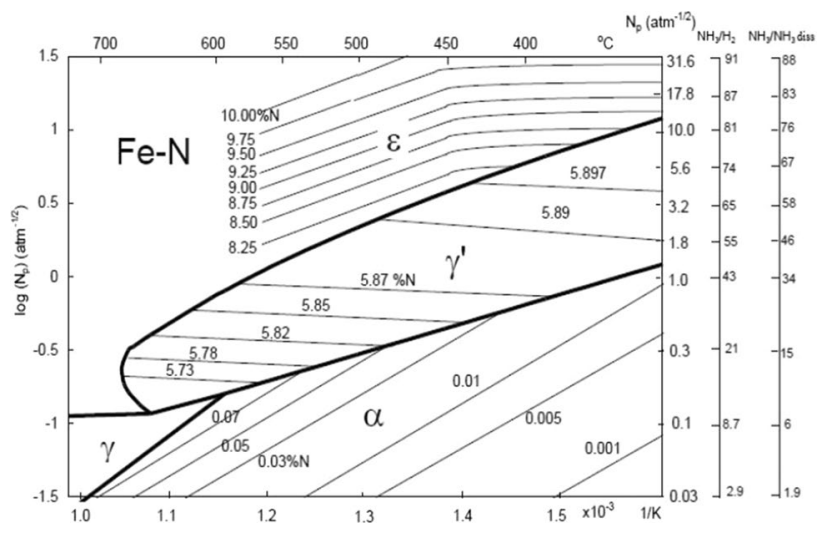

Fig. $2 \mathrm{Fe}-\mathrm{N}$ equilibrium diagram developed by E. Lehrer, modified by Małdziński [20-22]

(die no. 3). Potential values were accepted from the upper part of the range for each phase, due to the fact that the susceptibility of tool steels to nitrogen diffusion is lower than that of ordinary carbon steel, for which the diagram was plotted. The process temperature was accepted to be the upper temperature from the range of available temperature, to accelerate diffusion and reduce the time of the process. However, due to the risk of tempering of the die material at higher temperature, the temperature of $550{ }^{\circ} \mathrm{C}$ was not exceeded. The process was performed in two stages. First, a very high potential (above $15 \mathrm{~atm}-1 / 2$ ) at $490{ }^{\circ} \mathrm{C}$ was adopted to saturate the surface layer with nitrogen for a short time. Next, nitriding was performed with potential characteristic of the given $\gamma^{\prime}, \alpha$ or $\varepsilon$ phase structure, at $550{ }^{\circ} \mathrm{C}$.

Die no. 4 was subjected to the hardfacing process. A hardfacing product (weld metal) with the trade name Welding Alloys-Robotool 46 was used for hardfacing; the chemical composition of this hardfacing product is presented in Table 2 and the parameters of the applied hardfacing process are given in Table 3 .

The hardfacing process was performed according to specially developed Technological Welding Instructions (TWI). Immediately after hardfacing, the analyzed die was subjected to stress-relief annealing in a furnace at $450{ }^{\circ} \mathrm{C}$ for $4 \mathrm{~h}$ and was then slowly cooled along with the furnace.
Table 1 Applied variants of lifetime-improving die treatment

\begin{tabular}{llr}
\hline Die no. & Applied treatment & $\begin{array}{c}\text { Obtained } \\
\text { lifetime } \\
\text { [pcs.] }\end{array}$ \\
\hline 1 & Thermal treatment + nitriding for $\alpha$ diffusive layer & 10,000 \\
2 & Thermal treatment + nitriding for layer with $\gamma+\alpha$ phase structure & 7500 \\
3 & Thermal treatment + nitriding for layer with $\varepsilon+\gamma+\alpha$ phase structure & 6500 \\
4 & Thermal treatment + hardfacing with Robotool 46 material & 6900 \\
5 & Thermal treatment + hardfacing with Robotool 46 material + nitriding for $\alpha$ & 25,000 \\
& diffusive layer & \\
\hline
\end{tabular}


Table 2 Chemical composition of hardfacing product-

Robotool 46 powder wire

Table 3 Hardfacing process parameters

\begin{tabular}{lllllll}
\hline $\mathrm{C}$ & $\mathrm{Mn}$ & $\mathrm{Si}$ & $\mathrm{Cr}$ & $\mathrm{Mo}$ & $\mathrm{Ti}$ & $\mathrm{Fe}$ \\
\hline 0.20 & 0.90 & 0.50 & 5.10 & 3.80 & 0.25 & Rem. \\
\hline
\end{tabular}

\begin{tabular}{ll}
\hline Welding process & 138 (welding with powder metal-cored wire) \\
\hline Dimension of added metal $[\mathrm{mm}]$ & 1.6 \\
Current intensity [A] & Pass no.: \\
& $1-4-190$ \\
& $2-\mathrm{n}-285$ \\
Arc voltage [V] & Pass no.: \\
& $1-4-22.6$ \\
Type of polarity & $2-\mathrm{n}-31.5$ \\
Welding speed $[\mathrm{cm} / \mathrm{min}]$ & DC+ \\
Shielding gas & 30 \\
Gas flowrate $[1 / \mathrm{min}]$ & ISO $14175-\mathrm{M} 14-$ ArCO-5/2 \\
Free wire length [mm $]$ & $14-17$ \\
Positioning angle of welding clamp & $12-18$ \\
Pre-heating temperature $\left[{ }^{\circ} \mathrm{C}\right]$ & Perpendicularly to hardfaced surface \\
Interpass temperature $\left[{ }^{\circ} \mathrm{C}\right]$ & 350 \\
\hline
\end{tabular}

After hardfacing, the tool was mechanically processed by turning and grinding.

The chemical composition of the remelted zone of hardfaced layer is not uniform due to the intensive mixing of the material in the liquid state. Inside the remelted zone there is a boundary layer in which the mixing of the material is not complete. This layer is called the partial mixing zone. The padding weld was made in 2 padded layers, which means that the chemical composition of the partial mixing zone changes from the composition of the melted layer to the composition of the base material or the substrate. Therefore, the adopted technology assumes that after processing, the surface layer should consist of approx. $90 \%$ of the weld metal material.

Die no. 5 was subjected to hybrid treatment combining hardfacing and nitriding, where nitriding was realized in the same manner as in the case of die no. 4, while the nitriding process was realized according to a procedure making it possible to obtain a layer consisting of an $\alpha$ diffusive zone.

Dies prepared in this manner were subjected to operating tests. Each of the analyzed tools was exploited until determination by the process engineer, who conducted tests, that the tool should be withdrawn from operation due to wear. The process engineer, on the basis of observations and measurements carried out in accordance with the control plan, assesses the quality of the manufactured forgings and on this basis decides whether any defects are caused by tool wear, and if so, the tool is withdrawn from use. Table 1 gives the number of forgings forged using each of the tools, which corresponds to the obtained lifetime.

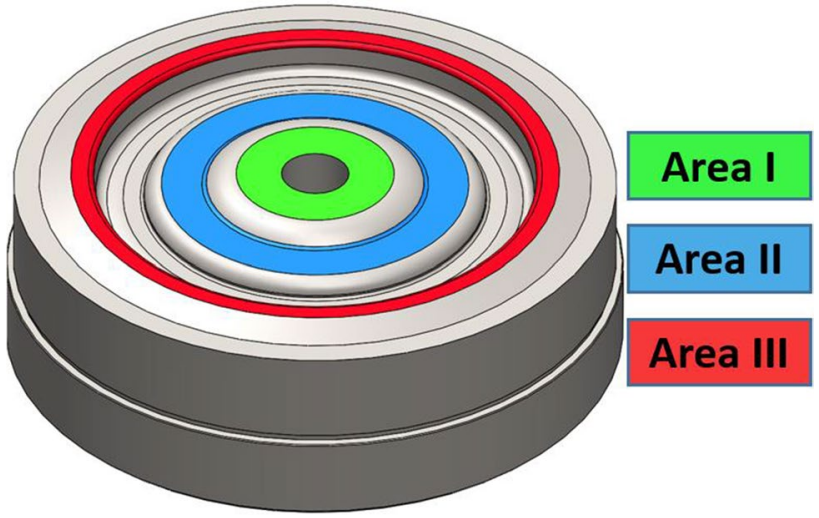

Fig. 3 Analyzed forging die with marked areas selected for tests

Next, after work, the tools were subjected to thorough analysis. Conducted tests included: macroscopic observations, microscopic observations using a scanning electron microscope of the working surface in selected areas, and microhardness measurements. Observations and tests were conducted in three characteristics areas, in which different working conditions were present due to shape (Fig. 3). Area I is exposed to the longest time of contact with the formed material of the forging, and because of this, the surface layer is heated the most in this area, and then, is intensively cooled. At the same time, as numerical simulation of this process [4] showed, the greatest unit loads occur in this area. In area II, both thermal and mechanical loads are moderate, which is why selection of this area for analysis enables 
observations of the preserved nitrided layer, which was most likely removed due to wear in other areas. Area III, covering the radius of the outlet to the die bridge, is characterized by the presence of a long friction path, which makes the dominant wear mechanism in this area abrasive wear.

Tests were also conducted on samples that were prepared so as to be representative with respect to the analyzed dies. Tests on samples covered determination of microhardness distributions and observation of the microstructure, which, for nitrided samples, was conducted using a Nikon Eclipse LV150 metallographic microscope. Meanwhile, for hardfaced samples, examinations of the microstructure were done using a Keyence VHX-6000 digital microscope with magnification up to $1000 \mathrm{x}$, with the capability of measurement under a variable lighting angle, depth of field composition in 2D and 3D, and HDR plus technology. The application of the this microscope makes it possible to present the entire hardfaced layer with individual layers of the pad weld, pad weld with substrate material, and transition of the heataffected zone (HAZ) into the native material (NM).

\subsection{Test results}

In relation to the fact that the tests conducted covered hardness measurements and observation of the initial microstructure of the surface layer for individual treatment variants, it was decided to present these results first. After that, detailed die test results following operating tests are presented.

\subsection{Analysis of microhardness distributions}

Microhardness measurements were performed using a LECO LM-100AT hardness tester, using the Vickers method, on the cross section in the direction from the working surface into the tool according to PN-EN ISO 65071:2007 guidelines, under a loading force of $0.98 \mathrm{~N}$. Obtained microhardness distributions are presented in the chart as a function of distance from the surface in a logarithmic scale, which was adopted to emphasize the changes visible in the $0.01-0.1 \mathrm{~mm}$, and significantly, in the case of hardfaced layers, to simultaneously indicate possible changes in the entire cross section of the pad weld, up to $10 \mathrm{~mm}$ (Fig. 4).

The assumption of the nitriding process applied to samples and tools was to obtain a diffusive layer with an effective thickness (according to the HV50 + criterion) of 0.13-0.15 mm. Determined microhardness measurements indicated variation of the nitrided layer's thickness obtained on the tested samples. The lowest effective thickness of the diffusive layer was obtained on the hardfaced sample, amounting to approx. $0.12 \mathrm{~mm}$. Meanwhile, the highest thickness of the diffusive layer was obtained in the nitriding process resulting in the layer with a $\varepsilon+\gamma^{\prime}+\alpha$ phase structure, with a total effective thickness equal to approx. $0.18 \mathrm{~mm}$. This can be explained by the fact that the alloying elements contained in the pad weld's material reduce the activity of nitrogen and increase or decrease the solubility of nitrogen in iron, which causes thickness reduction of the diffusive layer.

\subsection{Microstructure analysis}

Microstructure observations were conducted on sample cross sections etched with $3.5 \%$ Nital, and in the case of hardfaced layers, samples were etched with $5 \%$ Nital and Vilella's reagent. The image after hardfacing was analyzed throughout the entire cross section, with attention paid to the microstructure of individual layers and to transition zones. To prevent chipping off of the brittle nitride layer from sample surfaces during preparation of the metallographic specimen, samples were subjected to the nickel-plating process, which can be seen in Fig. 5 in the form of a thick, white layer.

Figure 5 presents the microstructure obtained on pilot samples in the controlled ZeroFlow nitriding process. The
Fig. 4 Initial microhardness distributions as a function of distance from surface determined on samples

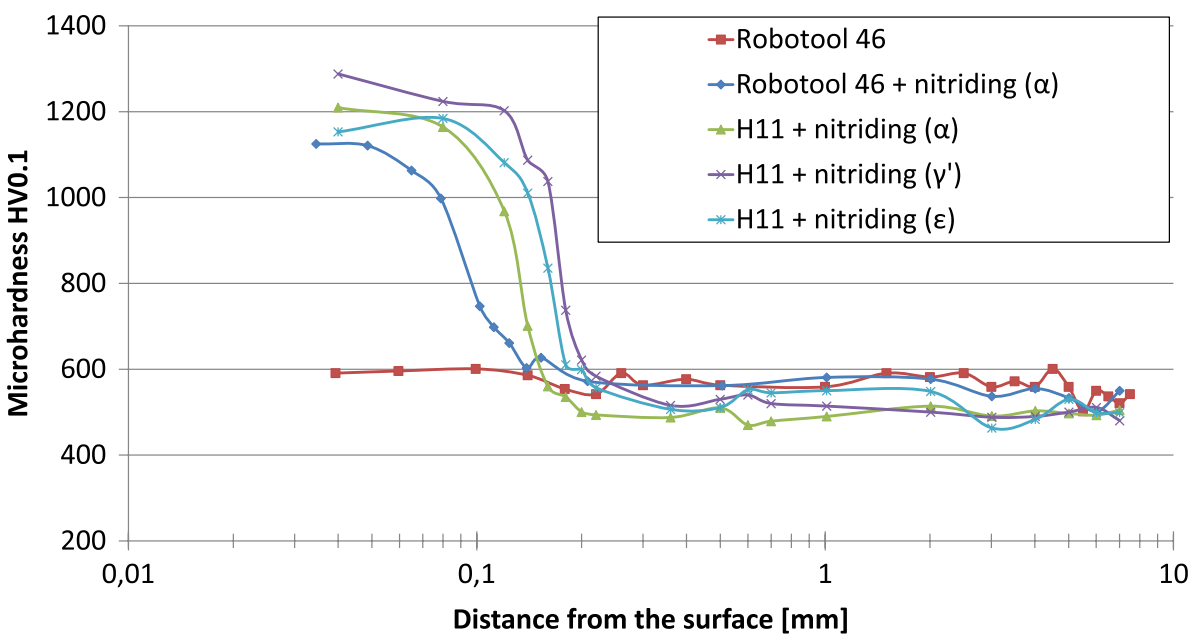


(a)

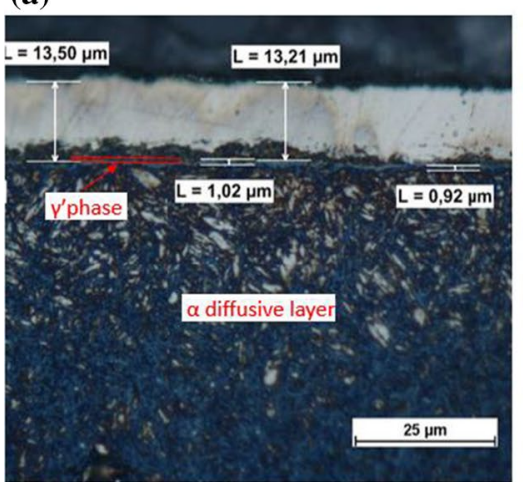

(b)

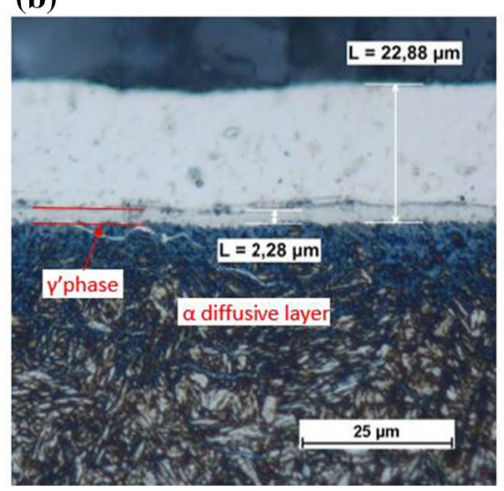

(c)

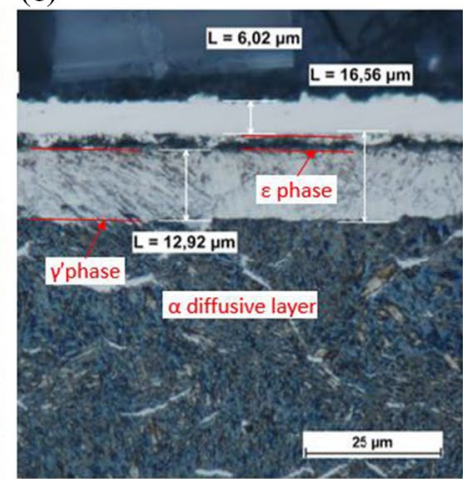

Fig. 5 View of nitrided layer's microstructure: $\mathbf{a} \alpha$ diffusive nitrided layer, $\mathbf{b}$ nitrided layer with $\gamma^{\prime}+\alpha$ phase structure, $\mathbf{c}$ nitrided layer with $\varepsilon+\gamma^{\prime}+\alpha$ phase structure

first of the obtained nitrided layer consisted of an $\alpha$ diffusive layer with a very thin (approx. $1.02 \mu \mathrm{m}$ ) layer of $\gamma^{\prime}$ nitride precipitates on the surface (Fig. 5a). In the next treatment variant, the obtained structure of the nitrided layer consists of a diffusive layer with precipitations of the $\gamma$ ' phase, particularly visible in the near-surface zone, and of a white layer of $\gamma^{\prime}$ nitrides on the surface, with a thickness of approx. $2.28 \mu \mathrm{m}$ (Fig. 5b). The third treatment variant made it possible to obtain a nitrided layer in which numerous, large precipitations of the $\gamma$ ' phase are visible in the diffusive zone, and near the surface, a thick (approx. $12.9 \mu \mathrm{m}$ ) layer of $\gamma^{\prime}$ and a discontinuous, thin layer of $\varepsilon$ iron nitrides with a maximum thickness of approx. 3-4 $\mu \mathrm{m}$ are visible (Fig. 5c).
The structure of the layer hardfaced with Robotool 46 material is shown in Fig. 6. The pad weld was made in 3 layers, as can be seen in the middle photograph, which shows a composite of the sample's entire surface (made from photographs taken at $200 \times$ magnification in the 3 D HDR system) from the surface layer down to the native material (NM). Based on observations, it can generally be stated that the quality of individual layers is high, and no welding defects were observed. Individual passes of the padding weld are well visible in the cellular-dendritic structure, and a rather wide $\mathrm{HAZ}$ can be seen in the native material.

A fine-grained structure of martensite from steel tempering is present in the structure of the native material (NM), with the presence of a small amount of residual austenite.

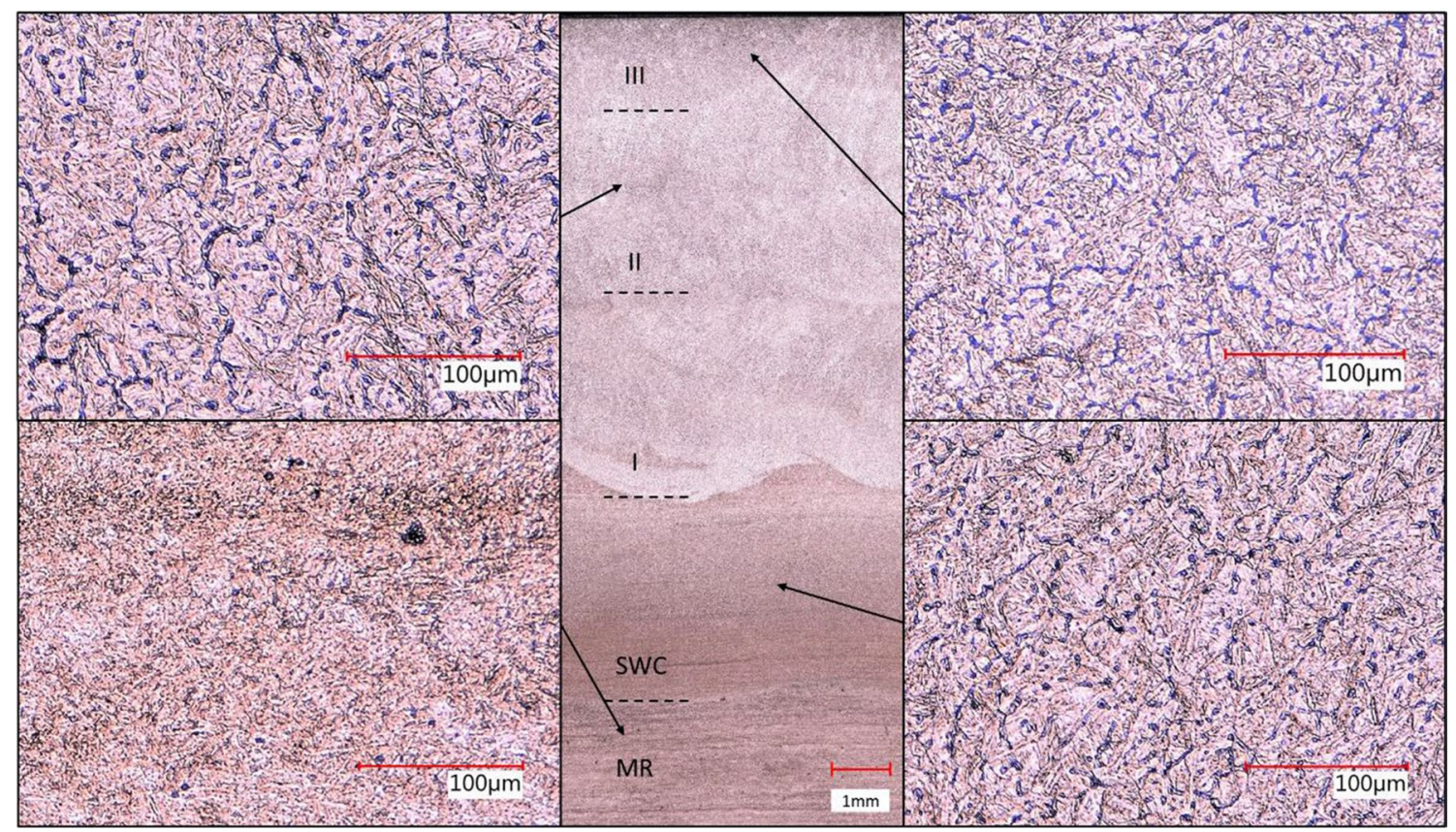

Fig. 6 Microstructure of layer hardfaced with Robotool 46 material 
The structure of the native material is characterized by banding with carbide precipitations. A wide HAZ, in which the steel's structure clearly changed, is visible in the upper part of the sample. Grains were refined, and banding was reduced. The structure of this area of the steel has the nature of tempering sorbite. The depth of fusion of the first layer is approx. $1 \mathrm{~mm}$, and the structure of the layer near the fusion line shows non-uniformity. A structure of this type forms in the case of a difference in chemical composition between the welding metal and substrate.

A coarse-grained bainitic-martensitic structure with a variable width of up to approx. $1 \mathrm{~mm}$ is present just under the fusion line. The structures of individual layers are similar and have a cellular-dendritic structure consisting of a fine-grained, low-tempered bainitic structure with a large amount of carbides present on grain boundaries (most likely chromium carbides) and a certain amount of carbides present inside grains. A small amount of residual austenite is also visible.

In the area of fusion between individual layers, grains were refined and there were an increased number of carbides in the structure due to the influence of heat supplied during application of the next layer. The final layer of the padding weld, particularly the surface part, consists of low-tempered martensite.

The structure of the sample subjected to hybrid treatment combining hardfacing and nitriding is presented in Figs. 1,
7. Similarly as in the case of the sample after hardfacing, individual passes of the padding weld and a rather wide $\mathrm{HAZ}$ are well visible. A wide HAZ is visible in the upper part of the sample. The structure of this area of the steel has the nature of tempering sorbite. The structure between individual layers shows changes on the fusion boundary due to heat supplied as a result of application of the next layer, with an elevated amount of carbides in the structure. The structure itself of individual layers is similar, consisting of a fine-grained, high-tempered bainitic structure with a large amount, larger than in the case of the sample that was not nitrided, of carbides present on grain boundaries (most likely chromium carbides) and a certain amount of carbides present inside grains. A small amount of residual austenite is visible on grain boundaries. The obtained nitrided layer consisted of an $\alpha$ diffusive zone.

\subsection{Macroscopic observations}

Macroscopic observations were conducted similarly to how they are done at the Forge during verification of tools' suitability for further operation. During the verification of the suitability of the tools for further operation, macroscopic observations are carried out with the naked eye, sometimes at low magnification, using a magnifying glass. The main goal is to identify cracks and assess the wear of the tool areas responsible for the formation of important elements of the

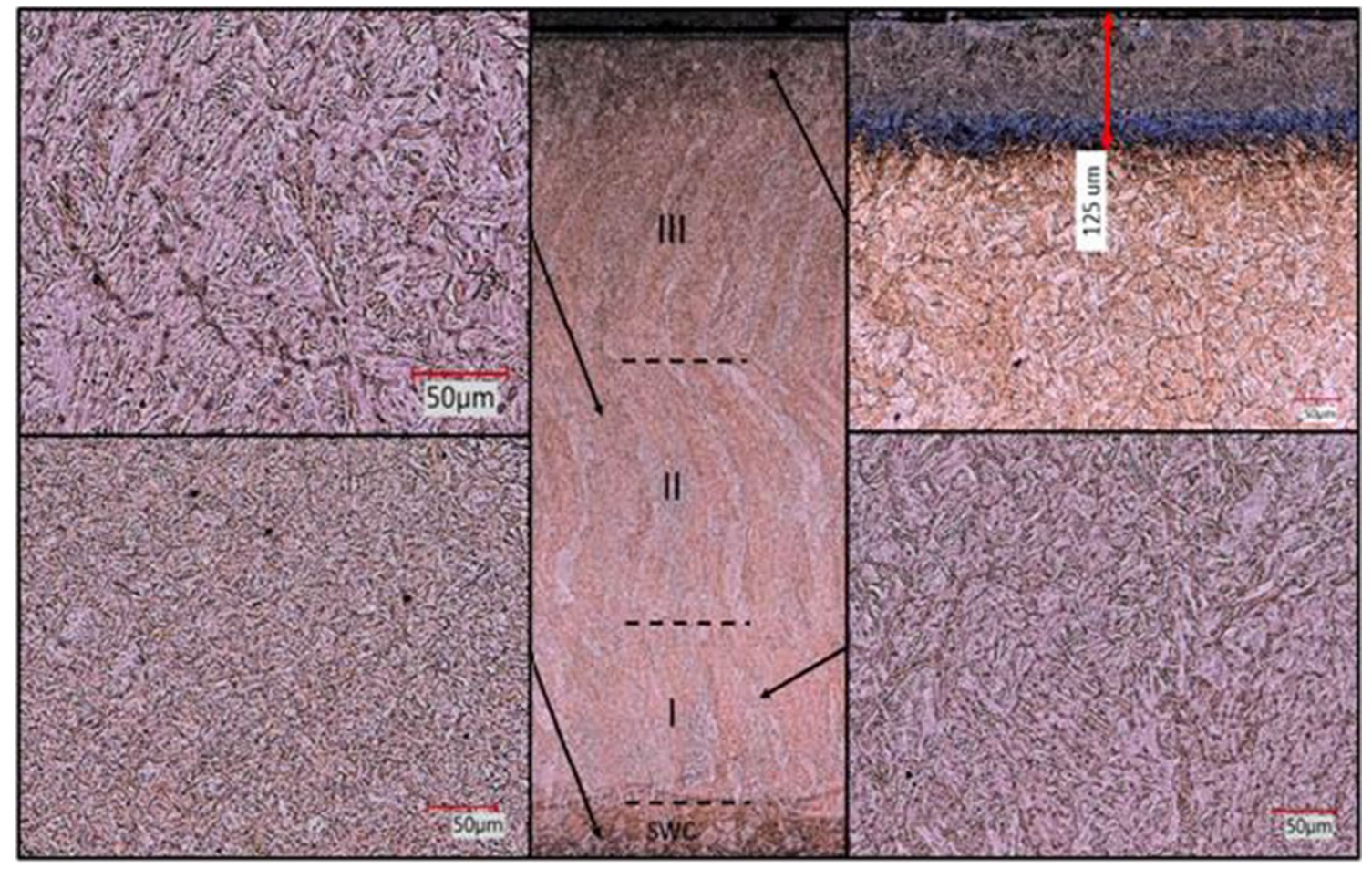

Fig. 7 Microstructure of the hybrid layer combining hardfacing with Robotool 46 material and nitriding with $\alpha$ diffusive layer 


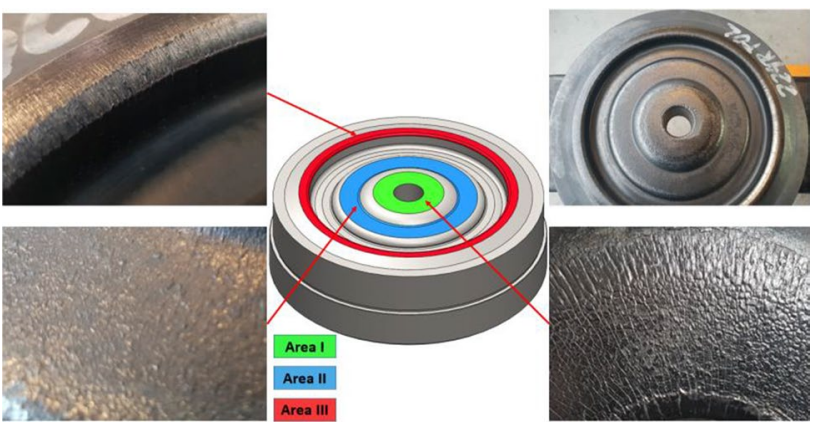

Fig. 8 Macro-view of the surface of die no. 1 after exploitation
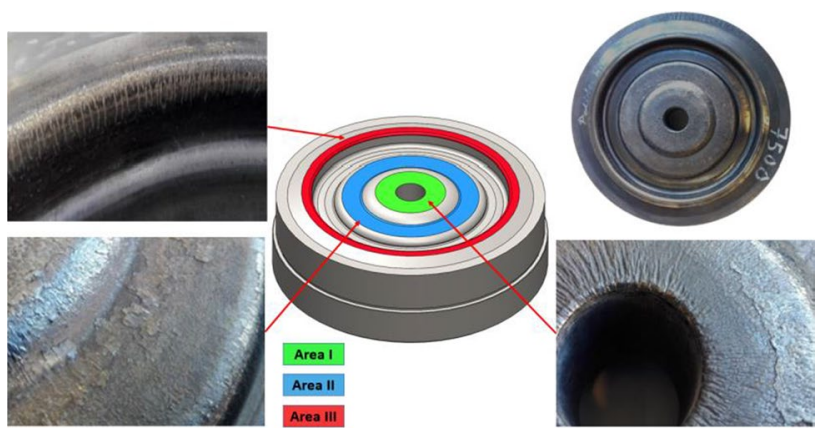

Fig. 9 Macro-view of the surface of die no. 2 after exploitation

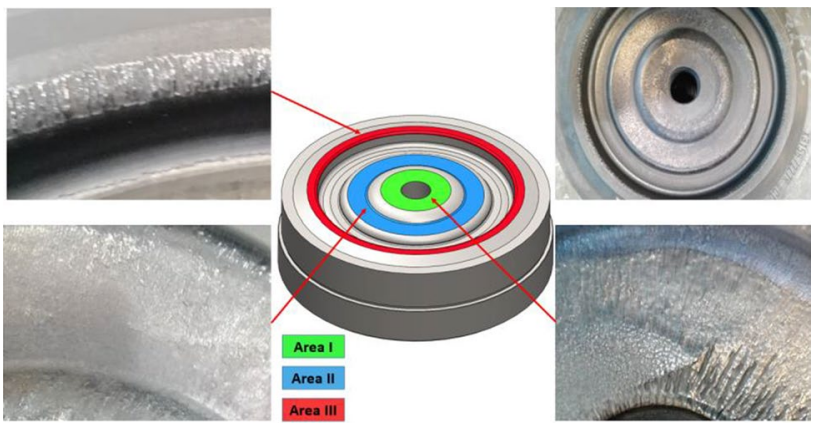

Fig. 10 Macro-view of the surface of die no. 3 after exploitation

forging, e.g., a code or number. Before observation, the tools are cleaned of contamination.

Analysis of this type allows for quick identification of the majority of significant types of damage, making it possible to make a decision regarding withdrawal of a die from further operation. The results of macroscopic analysis are presented in Figs. 8, 9, 10, 11, 12.

Macroscopic observations showed traces of various wear mechanisms such as abrasive wear, fatigue cracking and oxidation, which occurred with varying intensity in individual areas.

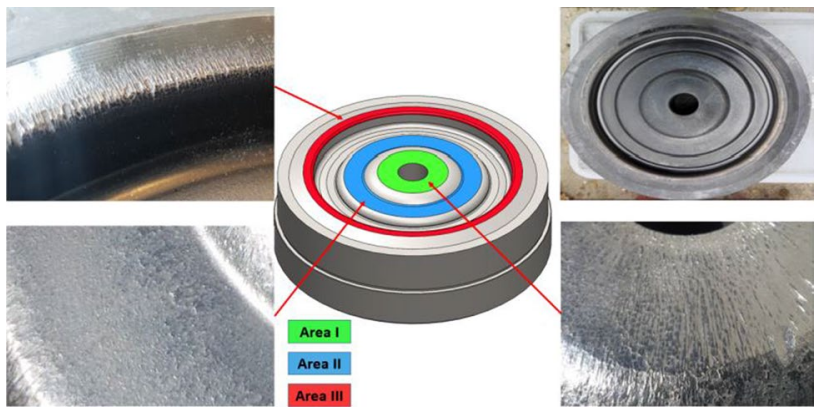

Fig. 11 Macro-view of the surface of die no. 4 after exploitation

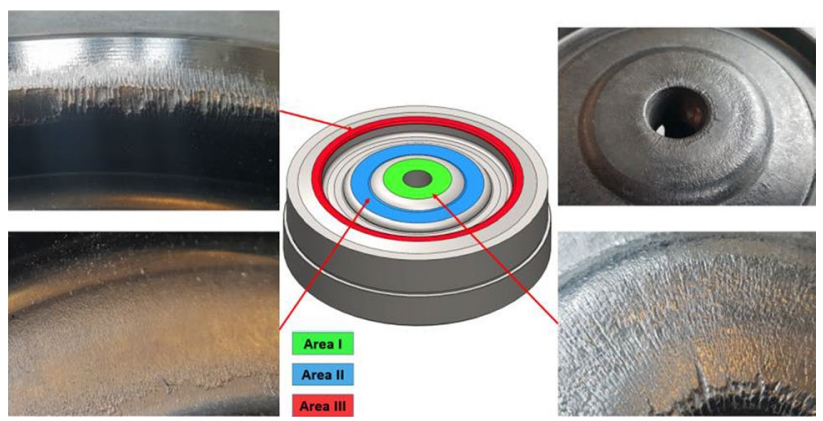

Fig. 12 Macro-view of the surface of die no. 5 after exploitation

In the case of die no. 1 , with an $\alpha$ diffusive layer, observations demonstrated traces of a mesh of thermo-mechanical cracks present throughout the entire surface, most intensively in area I (Fig. 8). Small traces of abrasive wear were determined in area III. Despite having produced the highest number of forgings, by a wide margin, this die, among the analyzed nitrided dies, exhibits wear traces that are clearly the smallest, which preliminarily suggests that the nitrided layer with the $\alpha$ diffusive layer effectively raises the lifetime of tools in the analyzed process.

On the surface of the die with $\gamma^{\prime}$ nitrides (Fig. 9), wear traces are mainly present in the central part (Area I), where they form characteristic furrows. Meanwhile, traces of material adhesion were observed in area II, which is an unacceptable phenomenon, as this reduces the surface quality of produced forgings.

Observations of die no. 3 showed the largest traces of wear, by far, in the central part of the die (area I). In this area, the crack mesh formed in the initial phase of exploitation was chipped off, and radially extending furrows typical of abrasive wear formed in its place (Fig. 10). The remaining tool surface is covered by numerous fine cracks typical of thermo-mechanical fatigue as well as abrasive furrows in area III.

Observations did not reveal significant traces of wear on the surface of die no. 4 (Fig. 11). A regular mesh of thermomechanical cracks is visible throughout the die's entire 


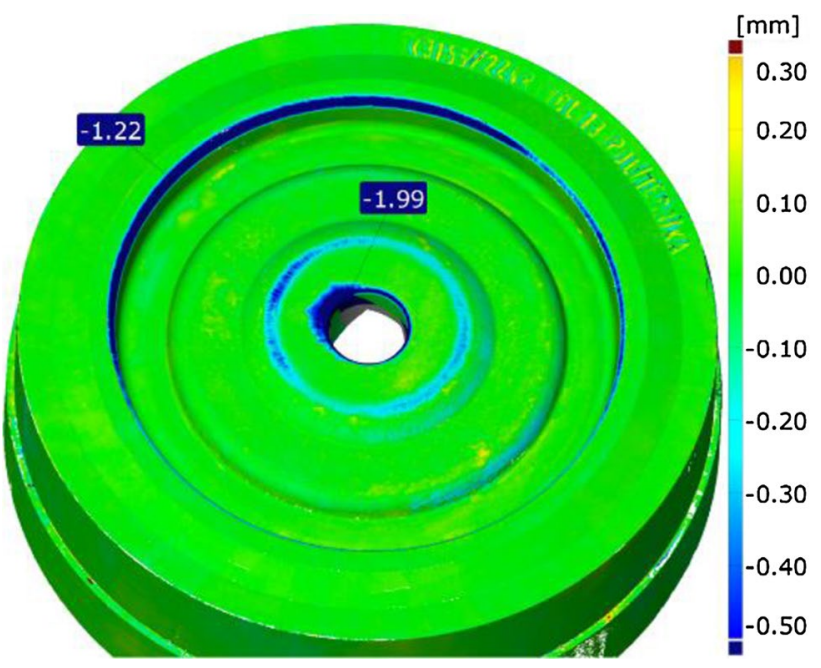

Fig. 13 Wear analysis of die no. 1 (with $\alpha$ diffusive layer) after 10,000 forgings

surface, and in area III, these cracks start succumbing to chipping, with abrasive furrows forming in their place.

Die no. 5, with the hybrid surface layer combining hardfacing and nitriding, despite having the longest time of operation, clearly exhibited the least traces of wear, which assume the nature of abrasive wear only locally in area III (Fig. 12), and the intensity and range of this wear are significantly lower than in the case of the other tools. Numerous fatigue cracks are present on the die's face surface, indicating thermo-mechanical fatigue. A small number of cracks extending radially from the die's center, which may indicate the beginning of abrasive wear in further operation, is also visible in this region.

The geometric quantity of wear was determined by means of 3D scanning using the Romer Absolute Arm 7520si measuring arm equipped with an RS3 laser scanner. Working surfaces of the studied dies were scanned before and after exploitation; then, data obtained were compared using the local best-fit algorithm in GOM Inspect software. The results of wear measurements are presented in the form of a color map of deviations, showing losses (blue and purple) and excesses (yellow and red) within the range $<-0.5 \mathrm{~mm}$, $0.3 \mathrm{~mm}>$. The results of analysis of individual dies are presented in Fig. 13, 14, 15, 16, 17.

Analysis of the geometric quantity of wear demonstrated that wear is present throughout the entire circumference in area III and is approx. $1.2 \mathrm{~mm}$ in the case of die no. 1. Wear traces were also observed in area I, and they are mainly situated in the vicinity of the ejector hole (Fig. 13).

In the case of die no. 2, with the $\gamma^{\prime}+\alpha$ phase structure in the nitrided layer, geometrically substantial wear, of approx. $1 \mathrm{~mm}$ (Fig. 14), was revealed by measurements in area I and area III after 7500 forgings were forged, where

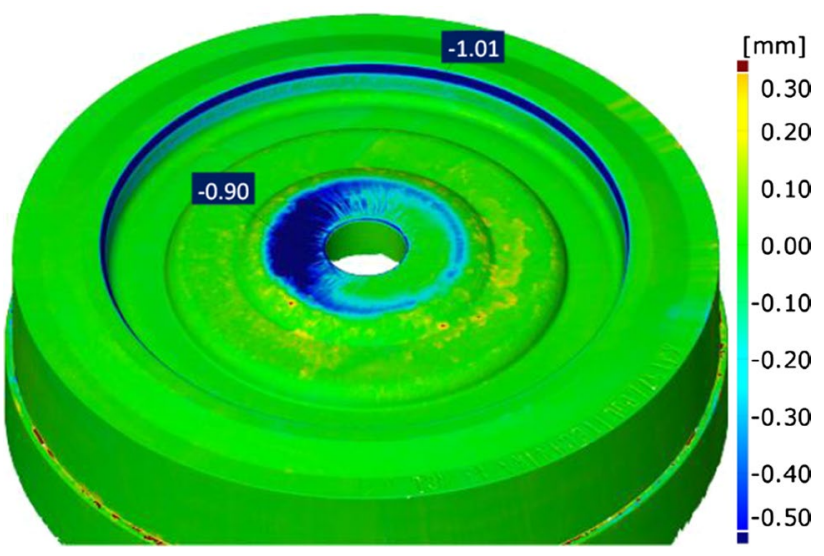

Fig. 14 Wear analysis of die no. 2 (with $\gamma^{\prime}+\alpha$ nitrided layer phase structure) after 7000 forgings

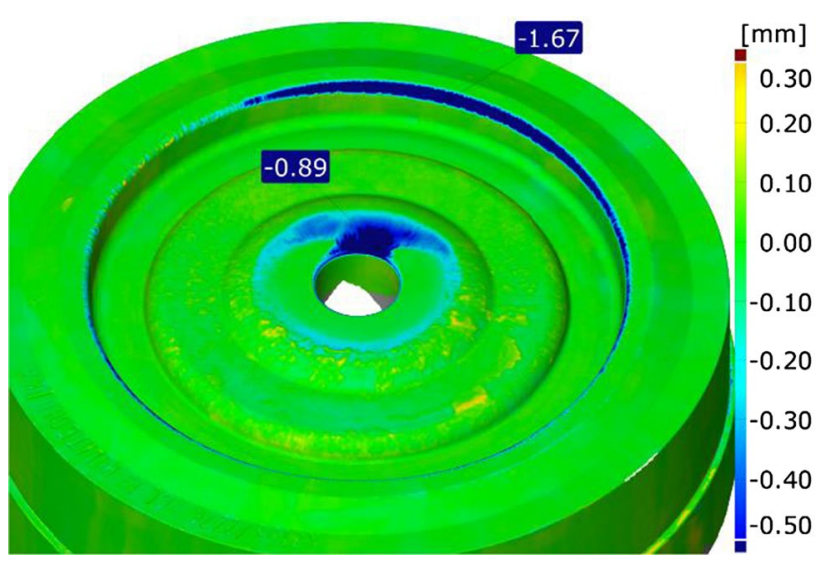

Fig. 15 Wear analysis of die no. 3 (with $\varepsilon+\gamma^{\prime}+\alpha$ nitrided layer phase structure) after 6500 forgings

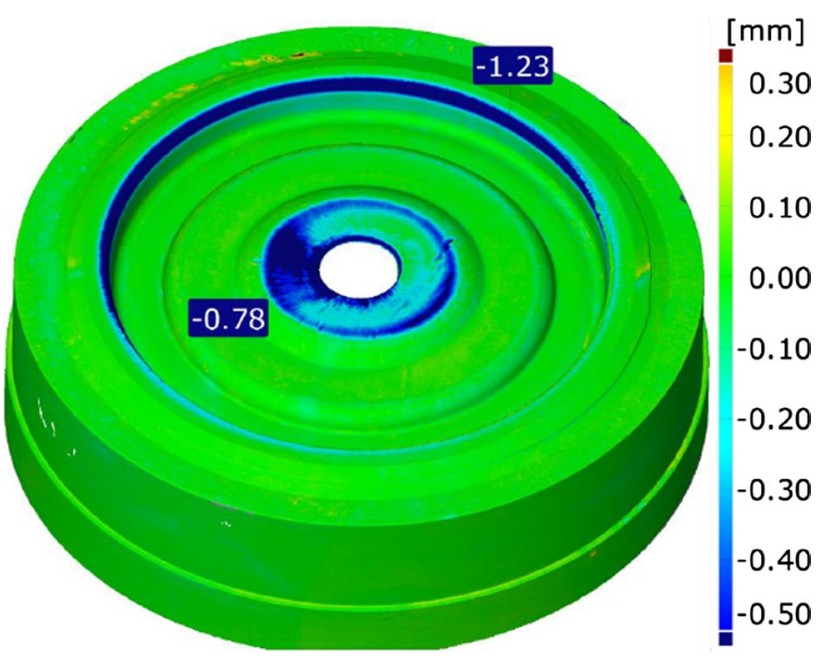

Fig. 16 Wear analysis of die no. 4 (hardfaced with Robotool 46 material) after 6900 forgings 

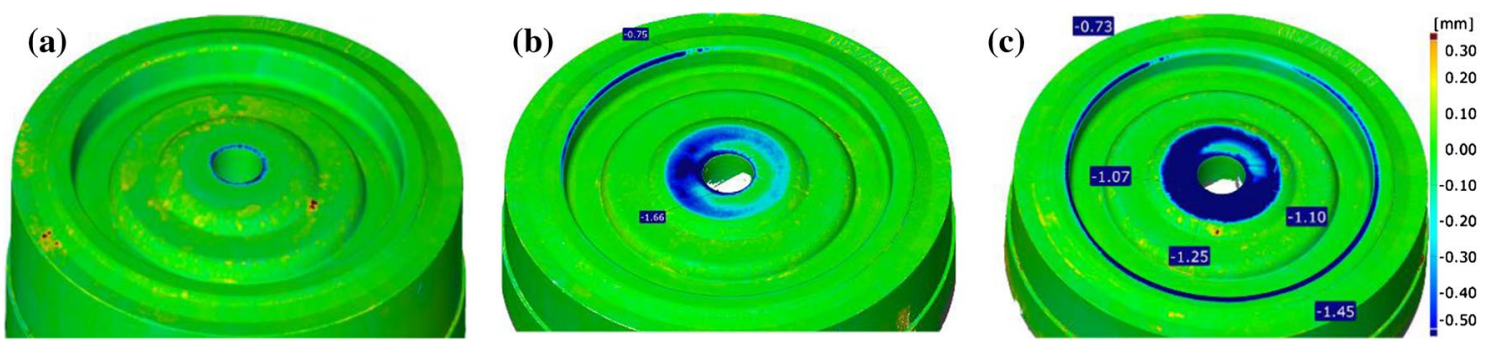

Fig. 17 Wear analysis of die no. 5 with hybrid layer combining hardfacing and nitriding: a after 9200 forgings, b 16,700 forgings, c 25,000 forgings

the wear in area III was uniform throughout the die's entire circumference.

Wear analysis of the die with the nitrided layer of $\varepsilon+\gamma^{\prime}+\alpha$ phase structure demonstrated large local material losses in area I and area III, reaching a value of approx. $1.7 \mathrm{~mm}$ (Fig. 15). This wear is typical for a nitrided layer of this type, where the layer of nitrides on the surface is chipped off and the particles removed locally intensify wear in the already weakened area.

The next analyzed treatment variant is the case with the application of hardfacing with Robotool 46 material (Fig. 16). Measurements revealed the presence of wear in the same areas as in the previous case, but here, the wear in area $I$ is more uniform and reaches a maximum value of about $1 \mathrm{~mm}$. Meanwhile, in area III, wear reaches a value of approx. $1.3 \mathrm{~mm}$.

In the case of the die with the hybrid layer combining hardfacing and nitriding, wear measurements were conducted in several stages after different operating periods, after 9,200 forgings, 16,700 and 25,000 forgings. (Fig. 17). After 9200 forgings, almost no wear was determined in the analyzed areas, and the wear on the edge of the ejector hole visible in Fig. 17 is probably due to oversaturation of the corner during nitriding and the occurrence of the unfavorable "edge effect". In the next image, obtained after forging of 16,700 forgings, non-uniform wear was identified in area I and II (Fig. 17b), the maximum value of which does not exceed $1 \mathrm{~mm}$. Finally, the die was exploited until it manufactured 25,000 forgings. Similarly as in the case of the other dies, no wear was observed in area II after 25,000 forgings (Fig. 17c). The wear in area I is rather uniform, and its maximum value does not exceed $1.3 \mathrm{~mm}$. At the same time, the wear in area III is low with respect to the number of forgings manufactured, and it is here that the die usually wears the most due to intensive friction.

\subsection{SEM observations}

Detailed analysis of the changes occurring in the surface layer was performed by means of a TESCAN VEGA III scanning electron microscope. Observations were conducted in the three areas marked in Fig. 3. Conducted observations made it possible to analyze destructive mechanisms.

Numerical simulations of the analyzed process showed that area I is the site most exposed to thermal loads [4]. This is the area that comes into the longest contact with the hot material of the forging, causing the surface layer's temperature to reach values even above $500^{\circ} \mathrm{C}$, which is followed by a sudden temperature drop as the stream of sprayed coolant and lubricant cools everything down. As a result of intensive periodic thermal loads caused by alternating heating and cooling of the die's surface in Area I, which is alternatingly stretched and compressed, thermal stresses arise, causing a mesh of microcracks to form. This form of destruction is defined as thermal fatigue, and it is present in all of the analyzed tools, and as can be seen in Fig. 18, the crack mesh observed on the surface of all analyzed treatment cases has a similar character. Differences are visible in the cross section of samples, where deformations in the surface layer can clearly be seen in the form of curved cracks (Fig. 18a-d). Only in the case of the die with the hybrid layer, combining hardfacing and nitriding, are cracks perpendicular to the surface visible (Fig. 18e). This indicates the higher resistance of the new hybrid layer, where tempering was caused by the long-lasting influence of high temperature.

In area II, where dies are under the lowest load, a regular mesh of thermo-mechanical cracks is visible on the surface (Fig. 19). Surface analysis in this area is rendered difficult by the presence of a large number of oxides, which are not naturally removed over the course of operation, as is the case in the other areas where intensive friction occurs. Meanwhile, it can be seen in the cross section that the least number of cracks are present in the case of the die with the hybrid layer, and the depth of these cracks does not exceed $100 \mu \mathrm{m}$ (Fig. 19e). This means that visible cracks are present in the diffusive zone of the nitride layer and do not propagate further into material, indicating fatigue resistance, which may be based on the presence of additional compressive stresses in the surface layer originating from the hardfacing and nitriding processes, limiting crack propagation.

Area III is where the largest geometric material loss was determined in all of the tested dies, reaching a value up to 
$1.5 \mathrm{~mm}$. This means that the nitrided layer was removed from the analyzed samples taken from this area at an earlier stage of exploitation. The nitrided layer was effective only in the initial stage of exploitation, and this extent of wear means that only the hardfaced layer remained.

Despite having the longest time of exploitation, by a wide margin, the die with the applied hybrid layer displayed similar wear in this area, within the range of $0-1.5 \mathrm{~mm}$. Fig. 20e shows similar, small traces of wear in the form of furrows typical of abrasive wear. Shallow fatigue cracks can be seen in the cross section, running perpendicularly to the surface, which indicates that the surface layer did not undergo plastic deformation, as in the case of the same area in other tools.

\subsection{Microhardness tests}

Analysis of microhardness changes in the surface layer of tools after exploitation was conducted only in area II, where no geometric loss was observed in all cases of the studied tools (Figs. 13, 14, 15, 16, 17). Substantial wear is present in the other areas, significantly exceeding the diffusive zone, which makes it difficult to interpret obtained results. Analysis of the area where no geometric wear is present will allow for evaluation of the resistance of the applied treatment variants to the action of high temperature throughout the entire period of exploitation. To show microhardness changes in detail throughout the entire hybrid layer, results obtained are (a)

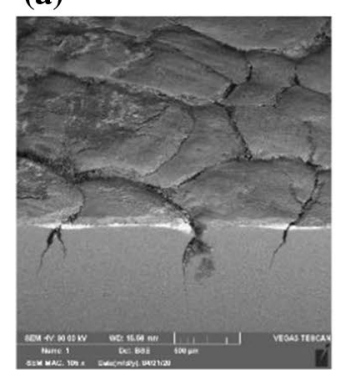

(b)

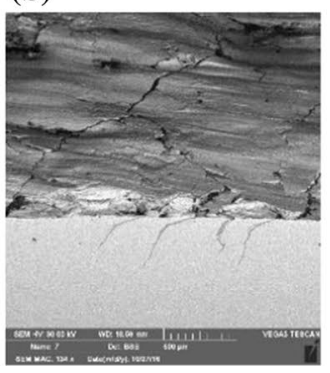

(c)

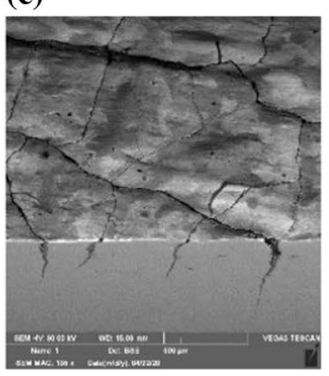

(d)

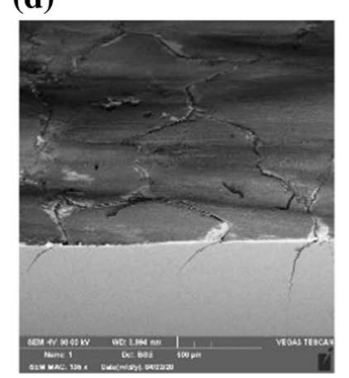

(e)

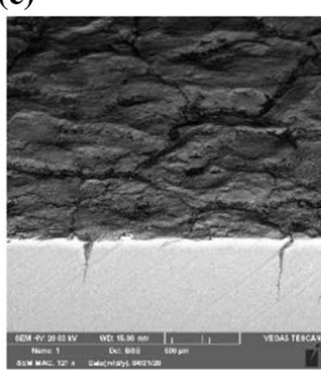

Fig. 18 SEM view of dies in area I: a die no. 1, b die no. 2, $\mathbf{c}$ die no. 3, $\mathbf{d}$ die no. 4, e die no. 5

(a)

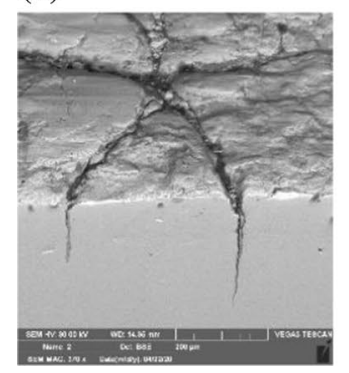

(b)

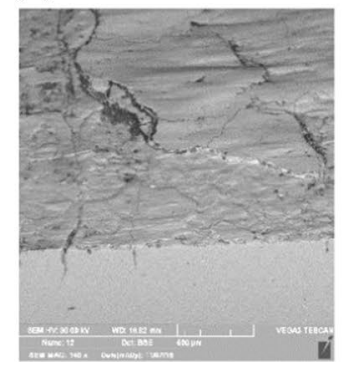

(c)

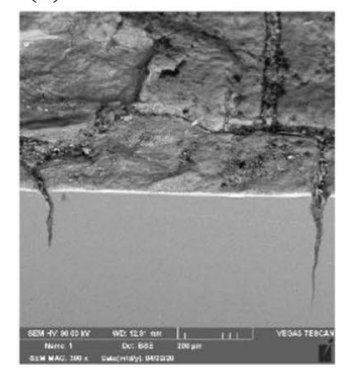

(d)

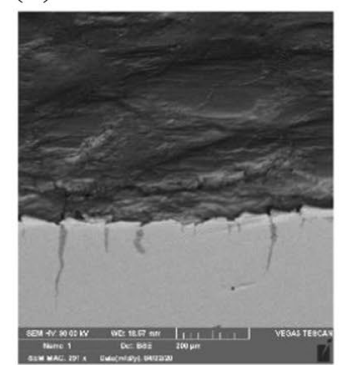

(e)

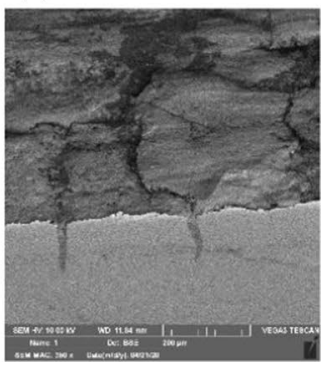

Fig. 19 SEM view of dies in area II: a die no. 1, b die no. 2, $\mathbf{c}$ die no. 3, $\mathbf{d}$ die no. 4, e die no. 5

(a)

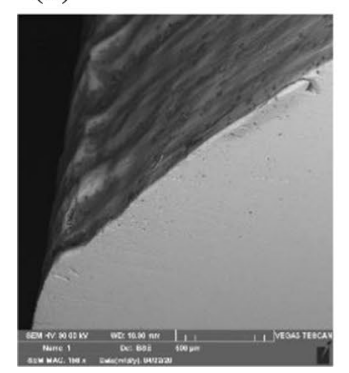

(b)

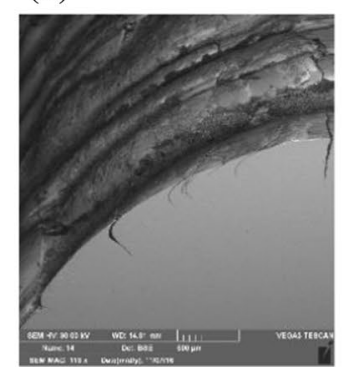

(c)

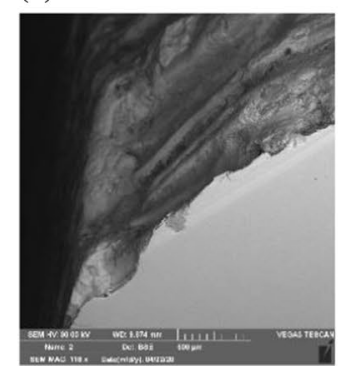

(d)

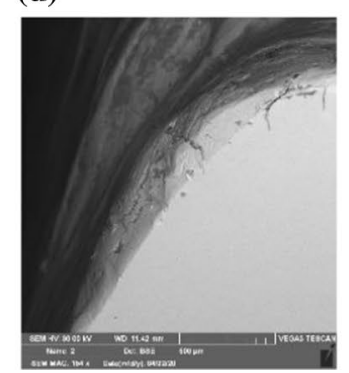

(e)

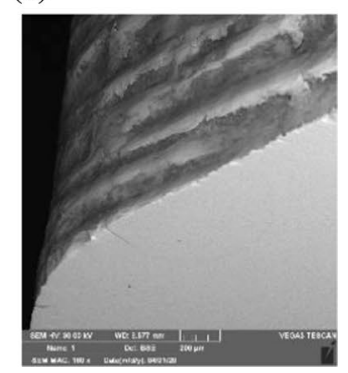

Fig. 20 SEM view of dies in area III: a die no. 1, b die no. 2, c die no. 3, d die no. 4, e die no. 5 
Fig. 21 Results of microhardness measurement in surface layer of tools in area II after exploitation

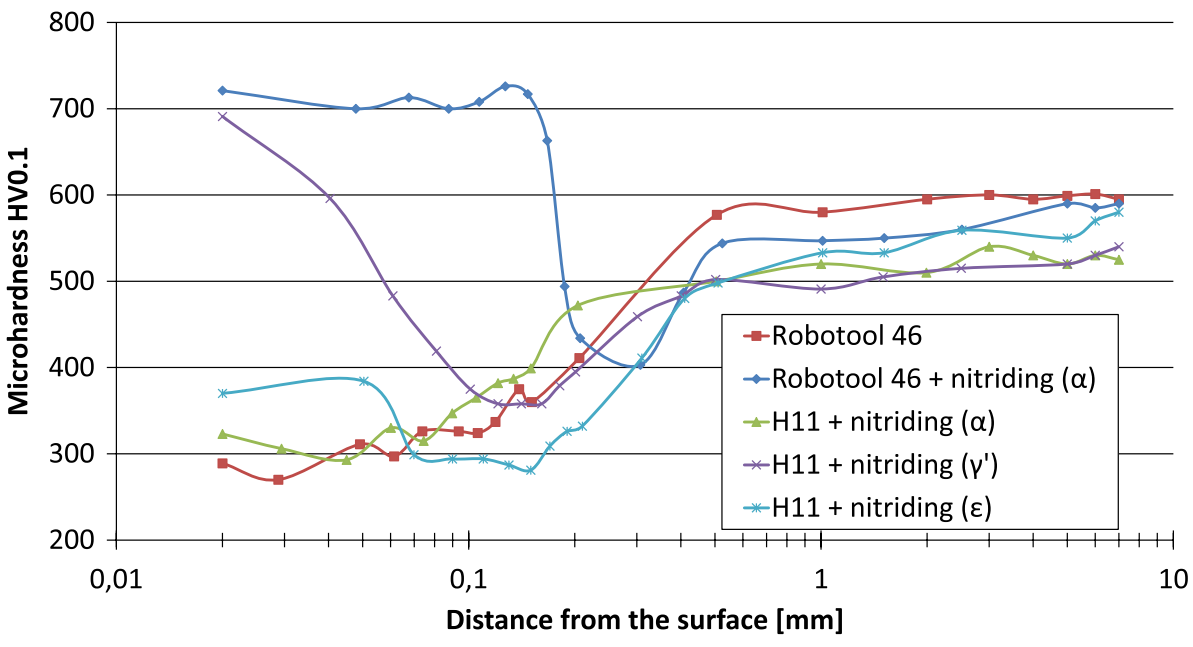

also presented as a function of distance from the surface in a logarithmic scale (Fig. 21).

The microhardness distributions obtained demonstrate clear differences in the resistances of individual tools to the action of elevated temperature. The maximum hardness dropped in comparison to the initial hardness measured on samples for all of the analyzed tools (Fig. 4). The greatest hardness drop was observed in tools with the $\alpha$ diffusive layer and the layer with $\varepsilon+\gamma^{\prime}+\alpha$ phase structure, where the hardness measured in the area of the working surface decreased to approx. 300-350 HV. It should be highlighted that, in the case of these tools, the surface layer underwent clear tempering, including below the nitrided zone, at a depth of $0.15-0.5 \mathrm{~mm}$, where a hardness drop to below $400 \mathrm{HV}$ was noted. A similar microhardness distribution was determined for the die with the hardfaced layer, which was tempered to a depth of approx. $0.5 \mathrm{~mm}$.

In the case of the die with the $\gamma^{\prime}+\alpha$ nitrided layer phase structure, the hardness directly in the near-surface area is maintained at the level of 700-600 HV, and a drop in hardness is observed under the nitrided layer, where hardness falls to a value of approx. $350 \mathrm{HV}$ at a depth of approx. $0.2 \mathrm{~mm}$.

Despite having the longest time of exploitation, the die with the applied hybrid layer displayed the highest resistance to the action of high temperature. The nitrided layer obtained on the hardfaced substrate retains a hardness of over $700 \mathrm{HV}$. A slight drop in hardness is observed under the nitrided layer, at a depth of approx. $0.2 \mathrm{~mm}$, where the hardness locally falls to the value of $400 \mathrm{HV}$ and then gradually increases to the initial value of the hardfaced substrate, to a value of approx. $550 \mathrm{HV}$.

\subsection{Summary and conclusions}

The comprehensive laboratory and industrial tests performed made it possible to compare the influence of the applied treatment methods on improvement of the lifetime of dies in hot forging processes. Laboratory tests, which were performed first on the samples, confirmed achievement of hardfaced and nitrided layers with the specific desired structures and properties. Next, industrial tests made it possible to verify wear resistance in the forging process. The results of tool analysis after the forging process revealed significant differences in the lifetime of individual tools and explained the scientific foundations of the results obtained. The results of this analysis led to the formulation of the following conclusions:

- nitriding may have a beneficial influence on improving the lifetime of forging tools, under the condition that the nitrided layer has an $\alpha$ diffusive layer structure, without a larger amount of $\gamma^{\prime}$ and $\varepsilon$ nitride precipitates

- hardfacing may be an effective method of improving lifetime, particularly from the perspective of increasing resistance to tempering under the influence of high temperatures, if the applied additional material contains appropriate alloying elements

- hybrid treatment by hardfacing and $\alpha$ nitriding clearly improves the lifetime of hot forging dies in terms of extending their time of exploitation- $\mathrm{n}$ the analyzed case by over $200 \%$ relative to the initial value

- hybrid layers combining hardfacing and nitriding improve resistance to tempering at high temperature as well as resistance to abrasive wear and thermo-mechanical fatigue

Funding This study was funded by the National Center for Research and Development, Poland (grant no. Lider X/0028/L-10/2018). 


\section{Compliance with ethical standards}

Conflict of interest The authors declare that there are no conflicts of interest regarding the publication of this paper.

Ethical issues as applicable This manuscript has not been published or presented else in part or in entirety and is not under consideration by another journal. We have read and understood your journal's policies, and we believe that neither the manuscript nor the study violates any of these. There are no conflicts of interest to declare.

Open Access This article is licensed under a Creative Commons Attribution 4.0 International License, which permits use, sharing, adaptation, distribution and reproduction in any medium or format, as long as you give appropriate credit to the original author(s) and the source, provide a link to the Creative Commons licence, and indicate if changes were made. The images or other third party material in this article are included in the article's Creative Commons licence, unless indicated otherwise in a credit line to the material. If material is not included in the article's Creative Commons licence and your intended use is not permitted by statutory regulation or exceeds the permitted use, you will need to obtain permission directly from the copyright holder. To view a copy of this licence, visit http://creativecommons.org/licenses/by/4.0/.

\section{References}

1. Gronostajski Z, Pater Z, Madej L, et al. Recent development trends in metal forming. Arch Civ Mech Eng. 2019;19(3):898-941.

2. Widomski P, Gronostajski Z. Comprehensive Review of Methods for Increasing the Durability of Hot Forging Tools. Proc Manuf. 2020;47:349-55.

3. Gronostajski Z, Kaszuba M, Hawryluk M, Zwierzchowski M. A review of the degradation mechanisms of the hot forging tools. Arch Civ Mech Eng. 2014;14(4):528-39.

4. Gronostajski Z, Kaszuba M, Polak S, Zwierzchowski M, Niechajowicz A, Hawryluk M. The failure mechanisms of hot forging dies. Mater Sci Eng A. 2016;82:1973-91.

5. Zwierzchowski M. Impact of tool magnetization on changes in the surface layer of forging tools. Arch Metall Mater. 2019;64:317-24.

6. Altan T, Ngaile G. Cold and hot forging: fundamentals and applications. Cleveland: ASM International; 2005.

7. Mrzygłód B, Hawryluk M, Gronostajski Z, et al. Durability analysis of forging tools after different variants of surface treatment using a decision-support system based on artificial neural networks. Arch Civ Mech Eng. 2018;18(4):1079-91.

8. Summerville E, Venkatesan K, Subramanian C. Wear processes in hot forging press tools. Mater Des. 1995;16(5):289-94.

9. Gronostajski Z, Kaszuba M, Widomski P, Smolik J, Ziemba J, Hawryluk M. Analysis of wear mechanisms of hot forging tools protected with hybrid layers performed by nitriding and PVD coatings deposition. Wear. 2019;420-421:269-80.

10. Deshpande M, Altan T. Selection of Die Materials and Surface Treatments for Increasing Die Life in Hot and Warm Forging. https://www.forging.org/uploaded/content/media/Altan_paper_ Die_materials_and_surface_treatments6.pdf.

11. Gronostajski Z, Widomski P, Kaszuba M, et al. Influence of the phase structure of nitrides and properties of nitrided layers on the durability of tools applied in hot forging processes. J Manuf Process. 2020;52:247-62.

12. Małdziński L. Termodynamiczne, Kinetyczne i Technologiczne Aspekty Wytwarzania Warstwy Azotowanej Na Żelazie i Stalach w Procesach Azotowania Gazowego. Poznań: Wydawnictwo Politechniki Poznańskiej; 2002.

13. Klimpel A. Napawanie i Natryskiwanie Cieplne. WNT; 2000.

14. Lazić V, Arsić D, Nikolić R, et al. Reparation of damaged forging dies by hard facing (HF) technology. Prod Eng Arch. 2015;6:26-9.

15. Gavalas E, Rossbach A, Feuerhack A. Performance analysis of laser-treated hot forging dies with WC-Co-Cr. Int J Adv Manuf Technol. 2020;106(3-4):1327-36.

16. Widomski P, Gronostajski Z, Kaszuba M, Kowalska J, Pawełczyk $M$. The laboratory tests of hybrid layers combining hardfacing and nitriding dedicated to increase the durability of forging tools in hot forging processes. Weld Technol Rev. 2019. https://doi. org/10.26628/wtr.v91i2.1020.

17. Kaszuba M, Widomski P, Białucki P, Lange A, Boryczko B. Laboratory tests of properties of the new-generation hybrid layers combining hardfacing and nitriding dedicated for improvement of forging tools' durability. Arch Civ Mech Eng. 2020;20:78.

18. Gronostajski Z, Widomski P, Kaszuba M, Zwierzchowski M, Hawryluk $M$. Influence of both hardfaced and nitrided layers on the durability of hot forging tools. Surf Innov. 2018;6(4-5):301-10.

19. Gronostajski Z, Kaszuba M, Widomski P (2019) Sposób poprawy trwałości narzędzia kuźniczego przez modyfikację jego warstwy wierzchniej

20. Lehrer E. Über das Eisen-Wasserstoff-Amoniak-Gleichgewicht. Zeit-schrift fur Elektrochemie. 1930;6(36):383-92.

21. Kowalska J. Symulator kinetyki wzrostu warstwy azotowanejnarzędzie wspomagające projektowanie procesów azotowania. Autobusy. 2016;12:1075-81.

22. Małdziński L., Ostrowska K., Okonowicz P., Hofman A., Kowalska J. Industrial gas consumption and emission in controlled gas nitriding using the ZeroFlow process and other established processes. Piece Przemysłowe \& Kotły I-II/2014

Publisher's Note Springer Nature remains neutral with regard tojurisdictional claims in published maps and institutional affiliations. 